\title{
Conhecimento e sinergia como indutores da inovação regional em turismo: o caso do Observatório do Turismo no Distrito Federal (Brasil)
}

\author{
Knowledge and synergy as inductors of regional innovation in \\ tourism: the case of the Observatory for Tourism at Federal District \\ (Brazil)
}

\section{El conocimiento y la sinergia como inductores de la innovación regio- nal en el turismo: el caso del Observatorio de turismo en el Distrito Federal (Brasil)}

\author{
Luis Henrique Souza ${ }^{1}$ \\ Luiz Carlos Spiller Pena ${ }^{2}$ \\ Marutschka Martini Moesch ${ }^{3}$
}

Resumo: 0 turismo é o lugar da inovação. A razão desta frase pragmática tem origem na multiplicidade de cenários competitivos que contextualizam empresas e destinos turísticos. A partir dos atuais paradigmas da competitividade, da satisfação e fidelização dos turistas e da oferta de experiências de valor, observa-se uma panóplia de inovações as quais desempenham um papel estratégico na gestão de destinos turísticos. Neste domínio, este artigo tem como objetivo realizar uma discussão sobre o tema inovação territorial em turismo com ênfase na troca de conhecimento e sinergia entre os envolvidos pela atividade turística. A metodologia utilizada consistiu na realização de uma análise da literatura sobre os temas inovação em turismo e inovação regional em turismo, utilizando, também, a abordagem qualitativa do estudo de caso acerca da implementação do Observatório do Turismo no Distrito Federal (Brasil) como prática de governança nesta região. Os resultados mostram que a participação do poder público e de instituições de ensino, além da cooperação entre os demais envolvidos por este desenho de governança, foram fatores chaves para a criação de uma plataforma inovadora para a gestão do turismo no destino.

Palavras-chave: Turismo. Inovação Regional. Conhecimento. Sinergia. Observatório. Distrito Federal.

1 Universidade Federal de Pernambuco (UFPE), Recife, PE, Brasil. Concepção e desenho do trabalho científico, formulação de ideias, redação do trabalho, preparação do artigo científico, análise dos dados; aprovação final.

2 Universidade de Brasília (UnB), Brasília, DF, Brasil. Redação do trabalho, formulação de ideias, coleta de dados, análise dos dados, aquisição e interpretação dos dados, revisão crítica.

3 Universidade de Brasília (UnB), Brasília, DF, Brasil. Formulação de ideias, coleta de dados, aquisição e interpretação dos dados revisão crítica.

Artigo recebido em: 23/02/2016. Artigo aprovado em: 13/10/2016. 


\begin{abstract}
Tourism is the place for innovation. The reason for this pragmatic sentence comes from the multiplicity of competitive scenarios that contextualize companies and tourist destinations. From the current paradigms of competitiveness, satisfaction and loyalty of tourists, and the offer of value experiences, it is noticed a panoply of innovations that perform a strategic role on managing tourist destinations. In this sense, this article aims to conduct a discussion about regional innovation in tourism with emphasis on synergy and shared knowledge among stakeholders involved with touristic activities. The methodology employed consists of literature review about innovation in tourism and regional innovation in tourism and also used the qualitative research approach at a case study which addresses the implementation of the Tourism Observatory at the Federal District (Brazil), as practice-based governance in that region. The results show that the participation of public sector and educational institutions, as well as the cooperation interplayed by the stakeholders involved by this governance design, were key drivers for creating an innovative platform for the tourism management at the destination.
\end{abstract}

Keywords: Tourism. Regional Innovation. Knowledge. Synergy. Observatory. Federal District.

Resumem: El turismo es el lugar de la innovación. La razón de esta frase pragmática viene de la multitud de escenarios competitivos que contextualizan las empresas y destinos turísticos. A partir de los paradigmas actuales de la competitividad, la satisfacción y la lealtad de los turistas y la oferta de experiencias de valor, hay una serie de innovaciones que desempeñan un papel estratégico en la gestión de los destinos turísticos. En este sentido, este artículo tiene como objetivo realizar una discusión de la innovación regional en el turismo con énfasis en el intercambio de conocimientos y la sinergia entre las partes interesadas para el turismo. La metodología utilizada consistió en una revisión de la literatura sobre la innovación en el turismo y los temas de innovación regional en el turismo, utilizando también la abordaje cualitativa de estudio de caso que se dirigió a la implementación del Observatorio de Turismo en el Distrito Federal (Brasil) como una práctica de gobernanza en esta región. Los resultados muestran que la participación de las instituciones públicas y educativas, además de la cooperación entre los implicados en este diseño de gobernanza, fueron factores clave para la creación de una plataforma innovadora para la gestión del turismo en el destino.

Palavras-clave: Turismo. Innovación Territorial. Conocimiento. Sinergia. Observatorio. Distrito Federal.

\section{INTRODUÇÃO}

A inovação no turismo é considerada uma temática premente e nitidamente transversal, com repercussões em múltiplas dimensões da atividade. Inovações em produtos e serviços, processos, gestão organizacional e mercado constituem o corpus principal das categorias de inovação (Hjalager, 2010). Desse modo, a inovação em turismo produz novos perfis de consumidores turistas, novas tendências e designs na oferta, novos modelos de gestão e distribuição de produtos turísticos.

No mundo globalizado, onde proliferam múltiplas opções de destinos a escolha do turista (Halkier, Kozak, \& Svensson, 2014), não causa surpresa a evidente constatação de que, diante da crescente competitividade no mercado do lazer e dos negócios das viagens, os destinos têm dado destaque às inovações nas experiências e nos serviços turísticos (Hall \& Williams, 2008; Hjalager, 2010). Aludindo-se a complexa relação encontrada na esfera do turismo e as instâncias regionais de governança engendra-se uma multiplicidade de ligações enredadas entre os diferentes envolvidos diretamente e indiretamente nas práticas do turismo, pelas quais se tornam possíveis a transmissão e consolidação de conhecimentos (Albernath \& Clark, 1985, Gibbons, 1994; Cooke, Uranga, \& Etxebarria, 1997), abrindo caminhos para a inovação.

Diante da perspectiva sistêmica, em que o turismo é visto como um sistema for- 
mado pelos conjuntos das (i) relações ambientais e seus subsistemas ecológico, social, econômico e cultural; ii) organizações estruturais e os subsistemas infraestrutura e superestrutura; iii) ações operacionais, formadas pelo mercado, oferta, demanda, produção, distribuição e consumo (Beni, 2001), crescem os estudos a cerca da ação cooperada no turismo, por meio das bases, dimensões e conceitos da inovação regional. Similarmente, este modelo holístico de análise estrutural do turismo pode avançar para a abordagem metafórica do ecossistema de negócios digitais (Alves, Vabo Junior, Vaz, \& Salomão, 2009), que se caracteriza por um sistema inteligente suportado por redes abertas, flexíveis e interativas estabelecidas em ambientes colaborativos (Gretzel, Werthner, Koo, \& Lamsfus, 2015).

A formação, identificação, construção e operacionalização de aglomerados ou ecossistemas enredados pelo turismo em sua dimensão regional conformam-se, na maioria dos casos, pelas políticas públicas encetadas com tais propósitos. O setor público é frequentemente um elemento chave e indutor dos sistemas de inovação em turismo, contribuindo, por exemplo, no desenvolvimento da capacidade estratégica, nas infraestruturas, no conhecimento baseado em pesquisas, nos dispositivos legais, e na oferta de instalações para aprimoramento das habilidades (Hjalager, 2010).

O presente artigo destaca um estudo de caso onde se analisa a relevância do poder público e das instituições de ensino e centros de investigação, bem como outros agentes ligados ao turismo, na coordenação de interlocuções e transferência de conhecimentos para potencializar a capacidade inovadora em sua dimensão regional De início apresenta-se a metodologia deste trabalho, seguindo-se de discussões sobre inovação no turismo e apresentação do estudo de caso do Observatório de Turismo do Distrito Federal (OTDF). Por fim, delineiam-se as principais evidencias desta experiência.

\section{METODOLOGIA}

No sentido de viabilizar as discussões teóricas propostas neste artigo, foi realizada uma análise da literatura durante o mês de junho de 2015 com referências extraídas em sua maioria a partir da base de dados SCOPUS. A priori, a busca se fez mediante a combinação das palavras "tourism" + "innovation" e "regional" + "innovation" + "tourism" o que resultou na utilização de 17 artigos científicos localizados no recorte temporal entre 1985 e 2015. O critério de seleção dos artigos se baseou na análise de conteúdo dos seus abstracts aprofundando-se quando necessário no texto completo. Também foram coletados os artigos pela significância dos registros em citações por outros autores.

Estes artigos encontram-se publicados nas seguintes revistas científicas: Research Policy (2); Tourism Management (2); Annals of Tourism Research (2); Journal of Sustainable Tourism (1); Journal of Destination Marketing \& Management (1); Current Issues in Tourism (1); Journal of Quality Assurance in Hospitality \& Tourism (1); Scandinavian Journal of Hospitality and Tourism (1); Journal of Travel Research (1); European Planning Studies (1); The Services Industries Journal (1); Tourism Geographies 
(1); Progress in Human Geography (1); (1) Computers for Human Behavior.

Somaram-se as referências de outras obras da literatura como: (i) tese de doutoramento, apresentando, desta forma, os resultados de investigações aplicadas e do estado da arte da temática; (ii) livros; (iii) capítulos de livros contendo artigos de autores que investigam na área da inovação e turismo; (iv) artigos publicados em anais de eventos científicos. Num esforço de síntese, a tabela 1 apresenta os principais temas discutidos nesta revisão de literatura.

Tabela 1 - Síntese de temas e autores discutidos na revisão de literatura

(continua)

Temas Autores

$\begin{array}{ll}\text { Inovação e produção } & \text { Scott e Laws (2006) abordam a perspectiva social do compartilhamento do co- } \\ \text { e transferência de co- } & \text { nhecimento, identificando relações de poder e controle nos destinos por parte } \\ \text { nhecimento } & \text { de operadores turísticos; }\end{array}$

Gibbons (1994) argumentam que os governos devem atuar como facilitadores do processo de produção do conhecimento, ampliando a permeabilidade entre as instituições;

Cooke et al. (1997) concluem que o aprendizado representa um elemento estratégico para os sistemas de inovação regional e defende o fortalecimento das capacidades regionais para promover a aprendizagem sistêmica e a inovação interativa.

Hjalager (2010) defende que quando as organizações do turismo estão engajadas em estruturas colaborativas, a capacidade para inovação e suas performances aumentam consideravelmente. Em turismo, o conhecimento é transferido através de quatro níveis sistêmicos: (i) trade, (ii) tecnológico; (iii) infraestrutural (representado pelos organismos públicos); (iv) regulatórios.

Usos da inovação em Hjalager (2010) indica que as inovações em Turismo podem ser enquadradas turismo nas seguintes categorias: produtos e serviços, as quais repercutem em mudanças observáveis pelos clientes; processos, que envolvem novos fluxos de ações com vista a promover eficiência e produtividade, fazendo uso extensivo de Tecnologias da Informação e Comunicação (TICs); inovações gerenciais, no âmbito da liderança e gestão de pessoas, na melhoria dos locais de trabalho, na retenção de talentos e no incentivo à disseminação do conhecimento; inovações em gestão, que dizem respeito às inovações no marketing de relacionamento entre empresas e consumidores.

Aldebert et al. (2011) salientam que as inovações em turismo têm aplicações no desenvolvimento de novos serviços, em processos das empresas turísticas e no marketing turístico, nos canais de distribuição do turismo.

Usos da tecnologia Buhalis e O'Connor (2006) destacam a tecnologia Internet como difusora do eem turismo commerce em turismo e o uso das tecnologias interativas das redes sociais que influenciam o comportamento de consumo dos turistas, com impactos na cocriação de valor e no e-WOM (eletronic Word of Mouth).

Hjalager (2013) aponta que smartphones e GPS melhoram a mobilidade dos turistas e as redes sociais facilitam a troca de informações entre turistas. 
Tabela 1 - Síntese de temas e autores discutidos na revisão de literatura

\begin{tabular}{ll}
\hline \multicolumn{1}{c}{ Temas } & \multicolumn{1}{c}{ Autores } \\
\hline Smart Tourist Desti- & Wang et al. (2013) realizaram um estudo empírico em 33 cidades da China e \\
nations & $\begin{array}{l}\text { concluíam que destinos turísticos inteligentes, além de disponibilizarem tecno- } \\
\text { logias de serviços "em nuvem" e "Internet das coisas", devem usar as tecnolo- } \\
\text { gias digitais para cocriar a experiência turística no destino. }\end{array}$ \\
& Minazzi (2015) sublinhou a importância da ubíqua conectividade online das \\
& smart destinations uma vez que smartphones provêm diferentes tipos de servi- \\
& ços que podem enriquecer a experiência turística, principalmente em termos de \\
& aplicativos baseados em localização, guias e compartilhamento de serviços de \\
& entretenimento. \\
Inovação regional em & Cooke et al. (1997) identificaram dimensões-chaves num sistema de inovação \\
turismo & regional no sentido de contribuir para a operacionalização do conceito. \\
& Brandão (2014) destaca a relevância da aprendizagem e do conhecimento para \\
& os sistemas de inovação regionais, cujas transferências de saberes podem ter \\
& origens tanto em redes formais como informais. \\
& Carson et al. (2014) apontam algumas barreiras existentes no engajamento dos \\
& sistemas locais do turismo nos processos de inovação regional, a exemplo da \\
& cultura de isolamento, incapacidades relacionadas ao aproveitamento das \\
& transferências de conhecimento, resistência à interação.
\end{tabular}

Fonte: Elaboração dos autores

No sentido de complementar as discussões referenciadas na literatura, foi escoIhida a opção metodológica do estudo de caso qualitativo descritivo que abordou a implementação de uma gestão participativa em turismo no destino Distrito Federal (Brasil). O estudo de caso caracteriza-se como uma estratégia de investigação cujo objeto é uma unidade específica ou sistema limitado que se analisa em profundidade (Hollinshead, 2004). As descrições foram fruto da participação efetiva e observação direta dos autores na implementação do Observatório de Turismo do Distrito Federal no período de 2009 a 2014. Sobretudo, foi um processo gerado a partir do Projeto dos 65 Destinos Indutores do Ministério do Turismo onde o trabalho de um Grupo Gestor do Turismo, formado por agentes do setor público e privado do turismo, facilitou, por meio de oficinas de planejamento, a construção de uma matriz de necessidades (a partir da metodologia deno- minada GUT - Gravidade / Urgência / Tendência) para a geração de um plano para o desenvolvimento do turismo no Distrito Federal.

\section{INOVAÇÃO E TURISMO}

A inovação no Turismo possui desdobramentos na competitividade entre as empresas do setor e nos destinos, na cooperação e produção de conhecimento, no atendimento às necessidades e desejos de turistas, na contribuição para a gestão sustentável dos recursos turísticos, na conectividade global dos destinos, na governança, na gestão e no marketing dos destinos e das empresas envolvidas com a produção da atividade turística. As inovações repercutem também na tecnologia, no desempenho econômico, no empreendedorismo, no papel do estado e na base territorial (Hall \& Williams, 2008).

O conceito de inovação, fundamen- 
talmente, perpassa a noção de processo social e coletivo, (Aldebert, Dang, \& Longhi, 2011) e envolve a produção e disseminação de conhecimento. Nesta acepção, inovação pode ser definida como a geração, aceitação e execução de novas ideias, processos, produtos ou serviços (Kanters, 1983, cit in Hall \& Willian, 2008). O novo ou a novidade é um conceito central para a inovação, porém, frequentemente, busca-se compreender a sua natureza, características e fontes procurando dirimir diferentes interpretações, problemáticas e ambiguidades.

De acordo com Williams e Shaw (2011), na perspectiva de Schumpeter, a novidade era concebida como um aspecto essencial da inovação, podendo assumir diferentes formas, a exemplo da criação de novos produtos, desenvolvimento de novas formas de produção, abertura de novos mercados, novas estruturas organizacionais. Dessa forma, classicamente, a inovação era estudada e analisada do ponto de vista da produção de novos bens tangíveis e patentes (Williams \& Shaw, 2011). Entretanto, a partir dos anos de 1980, a inovação no setor de serviços, incluindo-se o Turismo, tem merecido maior atenção por parte dos pesquisadores (Hjalager, 2010)

As inovações podem provocar disrupções, melhorar produtos e serviços ou até destruir ou tornar obsoletas competências consolidadas (Albernath \& Clark, 1985). Lemos (1999) descreve dois tipos de inovação: (i) a inovação radical, a qual provoca uma ruptura estrutural no padrão tecnológico existente, refletindo nos processos organizacionais e no comportamento dos consumidores, originando novas indústrias, novos produtos e mercados; (ii) a inovação incremental, a qual é responsável pelo aperfeiçoamento nos produtos ou processos, sem alterações na estrutura industrial. Chang, Go e Pine (1998) ainda identificam um terceiro tipo denominado inovação distintiva que demanda adaptações no comportamento do consumidor e nos processos organizacionais.

Por sua vez, Hjalager (2010), com propósitos analíticos, indica que as inovações em Turismo podem ser enquadradas nas seguintes categorias: (i) produtos e serviços, as quais repercutem em mudanças observáveis pelos clientes; (ii) processos, que envolvem novos fluxos de ações com vista a promover eficiência e produtividade, fazendo uso extensivo de Tecnologias da Informação e Comunicação (TICs); (iii) inovações gerenciais, no âmbito da liderança e gestão de pessoas, na melhoria dos locais de trabalho, na retenção de talentos e no incentivo à disseminação do conhecimento; (iv) inovações em gestão, que dizem respeito às inovações no marketing de relacionamento entre empresas e consumidores; (v) as inovações institucionais, que correspondem a estruturas organizacionais que eficientemente redirecionam ou aprimoram os negócios no turismo e conformam-se no âmbito das redes e alianças empresariais e territoriais.

Estudos realizados por Aldebert et al. (2011) elucidam que as inovações em turismo incidem em grande parte no desenvolvimento de novos serviços, havendo também inovações em processos e no marketing. Semelhante conclusão foi apresentada por Brandão (2014), em que os propósitos mais significativos em direção à inovação no tu- 
rismo são a troca de conhecimento, desenvolvimento de novos produtos e estratégias de marketing.

As inovações relacionadas à tecnologia Internet redesenharam profundamente a estrutura da indústria do turismo, a natureza dos produtos turísticos e experiências, a competitividade e o processo de criar valor no turismo (Sigala, 2014). Os avanços na tecnologia permitiram a difusão do e-commerce e, dessa forma, portais online de vendas de passagens aéreas e reservas em hotéis foram viabilizados, além da difusão das redes sociais para uso dos viajantes e seus impactos na cocriação de valor e no eletronic Word-ofMouth (e-WOM) $)^{4}$. Buhalis e O'Connor (2006) apontam a comodidade, a possibilidade de montar viagens conforme as preferências mais específicas para consumidores exigentes e experientes, as integrações de negócios com as redes de cartões de crédito e financeiras e as políticas de redução de custos por parte dos fornecedores de serviços turísticos como fatores responsáveis pela expansão das vendas de serviços turísticos online.

As inovações no turismo também possibilitam: (i) o aumento de produtividade e eficácia para as empresas do turismo; (ii) a melhora na mobilidade dos turistas pelo uso de smartphones e Global Position Systems (GPS's) nos destinos; (iii) a troca de informações entre organizações; (iv) a formação de novos destinos; ( $v$ ) a oferta de equipamentos que oferecem conforto aos turistas (Hjalager, 2013). Observam-se, também, impactos no comportamento do consumidor turista, onde a tecnologia da Internet permite uma maior segurança na tomada de decisão e avaliações pós-consumo, com importantes contributos para o marketing. Também se destaca a importância das mídias sociais, cujos aspectos inovadores estão reformulando as práticas de marketing dos destinos (Hjalager, 2010). As teorizações e exemplos ora ilustrados destacam a capacidade da Inovação no turismo para vender e gerar negócios. Neste âmbito, a tecnologia é vista como solução para criar valor e novos serviços no Turismo. A tecnologia estreita a difusão e o compartilhamento de saberes, construindo a égide da sociedade informacional (Castells, 2007).

As inovações tecnológicas estão na origem da difusão do turismo, notadamente, aquelas associadas aos sistemas de comunicação e de transportes, esse último com as linhas férreas, o automóvel e o transporte aéreo figurando como inovações que mudaram o curso do turismo (Hjalager, 2013) e da própria sociedade. Já as Tecnologias da Informação e das Comunicações (TICS) continuam a produzir inovações no âmbito dos destinos com impactos na (i) experiência do turista; (ii) na construção de base de dados inteligentes e dinâmicas; (iii) no marketing; (iii) nas estratégias de comunicação entre os turistas e as Destinations Marketing Organizations (DMOs) e os turistas entre si (e-WOM); (iv) e na competitividade nos destinos (Hjalager, 2013). Emergiu, dessa forma, o conceito de

produtos e serviços em ambientes online. Comentários dos turistas deixados em portais de reservas são exemplos de $e$-WOM. 
Smart Tourism Destinations (STDs), consistindo em plataformas de suporte à informação relacionadas às atividades dos turistas, ao consumo de produtos turísticos e ao status dos recursos turísticos e que podem ser instantaneamente integrados e disponibilizados para outros turistas, empresas e organizações através de uma variedade de aplicativos (Wang, Li, \& Li, 2013).

As STDs consolidam a tônica da conectividade e interatividade, as quais são características da futura Web 3.0 (Minazzi, 2015), facilitando a mobilidade dos turistas pelo destino e recebendo e repassando informações sobre o uso dos serviços turísticos. O backstage das STDs utiliza as tecnologias Cloud Services ${ }^{5}$, The Internet of Things $^{6}$ e End-User Internet Service System ${ }^{7}$ como soluções para prover vantagem competitiva aos destinos (Wang et al., 2013). $\mathrm{O}$ acesso a tais tecnologias ainda é relativo no que diz respeito à inclusão da totalidade dos agentes envolvidos com o turismo nas destinações. Entretanto, nota-se que as plataformas de financiamento coletivo com o suporte das TICs possibilitam a realização de projetos de turismo apoiando comunidades que muitas vezes não possuem expertise para desenvolver uma campanha de financiamento coletivo, ou não conseguiriam acessar outro tipo de financiamento para seus projetos (Cezário \& Pena, 2016). O financiamento coletivo, inclusive para o turismo, revoluciona a cooperação em redes quando propicia a colaboração solidária entre consumidores e organizações populares num movimento de crescimento conjunto, contrário à lógica do capitalismo na medida que promove o bem estar a todos os seus integrantes (Mance, 2002, cit in Cezário, Pena, 2016). Diante destas questões, a inovação possui reflexos diretos na competitividade e no desenvolvimento de destinos turísticos e o próximo item discutirá o papel da inovação nas regiões turísticas.

\subsection{Inovação regional em turismo}

A colaboração em rede e um comportamento que favoreça a troca de conhecimento entre os envolvidos com a atividade turística têm sido objeto de pesquisas e análises no âmbito das relações entre inovação, turismo e região. Aprendizagem e conhecimento representam elementos estratégicos em qualquer processo de inovação (Cooke et al., 1997; Brandão, 2014). Dessa forma, Abernath e Clark (1985) reconhecem que "a inovação é derivada da ciência e sua introdução torna o conhecimento existente e sua respectiva aplicação obsoletos" (p. 6-7). Por outro lado, enquanto Abernath e Clark (1985) associam inovação como derivada do avanço científico e, por essa via, assente em conhecimento explícito formal e sistemático, Scott e Laws (2006) reconhecem a existência do conhecimento tácito, o qual é

\footnotetext{
6 The Internet of things diz respeito à conexão de equipamentos ou utensílios do dia a dia à rede mundial de computadores.

7 End-User Intenet Service System relaciona-se ao conjunto de equipamentos e aplicativos que dão suporte aos Cloud service e a The Internet of things (Wang et al., 2013).

${ }^{5}$ Cloud service refere-se ao acesso conveniente a diversos aplicativos, dados e softwares através de browsers Internet. Em linhas gerais, no cloud services o usuário não precisa instalar aplicativos e programas em seus dispositivos, e sim acessar um endereço Web que os contem armazenados.
} 
radicado na ação e produzido de modo informal, como gerador de novas formas de inovação.

Gibbons (1994) explica que o conhecimento tácito advém de uma variedade de fontes: (i) eletronicamente; (ii) organizacionalmente; (iii) socialmente, (iv) informalmente; (v) através de redes de comunicações. De modo semelhante, Brandão (2014) comprova em seus estudos que o conhecimento incorporado em recursos humanos, clientes e contatos pessoais ou informais (capital social decorrente da participação em redes informais) também pode ser considerad o fonte de conhecimento para a inovação em Turismo. O conhecimento também pode ter origens (i) no fazer, através do aprender com a experiência; (ii) pela interação; (iii) pela atuação de específicas estruturas institucionais; (iv) por mudança cultural (Cooke et al., 1997). Através destes conceitos, emerge a importância da produção e transmissão de conhecimento, quer de forma explicita ou tácita, quer para a inovação no domínio das regiões turísticas.

Cumpre destacar o papel do conhecimento na inovação no Turismo. O turista atual é mais experiente, informado e exigente em suas escolhas, procura a autenticidade e singularidade nos destinos e deseja fazer de sua viagem uma experiência onde o conhecimento e aprendizado são aspectos centrais em suas motivações. Este perfil pressiona os destinos para serem mais inovadores e, dessa forma, ampliarem sua atratividade na economia turística globalizada (Halkier et al., 2014). Inovações estas que podem au- xiliar o turista em suas buscas por experiências mais autênticas e únicas nos destinos. Neste domínio, Cherly e Chris (2013) apontam a interação entre as organizações no nível do destino, conformando redes de governança, como uma estratégia para assegurar a colaboração e criação de um meio ambiente que suporta a inovação pelo conhecimento.

Hoarau e Kline (2014) ressaltam o aspecto do compartilhamento do conhecimento entre turistas e as empresas turísticas, onde a inovação surge através da cocriação, ou seja, das práticas relacionais entre os prestadores de serviços e seus clientes. Os autores concluem que o conhecimento tácito é importante para incrementar melhorias nos produtos e serviços turísticos e a introdução de inovações. Além dos processos de cocriação entre clientes e empresas turísticas, Hoarau e Kline (2014) apontam a competência social no âmbito das relações entre as organizações turísticas e seus empregados como especialmente importante para a aquisição de conhecimento e sua absorção e assimilação para gerar inovação. Para Cherly e Chris (2013), a inovação é a chave do sucesso para os destinos no mercado turístico e a sua base está na geração, transferência e uso de novos conhecimentos em Turismo. Os destinos devem ser orientados pela inovação e pelas suas marcas para assegurarem crescimento futuro e sustentado (Zhang \& Xiao, 2014).

Nas teorizações acerca da gestão do Turismo há um consenso na literatura sobre a necessária orquestração de esforços entre comunidade, empresas e instituições para potencializar as regiões na direção da inova- 
ção da atividade turística nos destinos (Hall \& Willian, 2008; Hjaleger, 2010; Carson, Carson, \& Hodge, 2014). O conceito de sistemas de inovação regional emerge, portanto, a partir do contexto da formação de redes, dos canais de negócios, da governança, da interação e dos Sistemas Produtivos Locais (SPL), onde o processo de transferência de conhecimento é pré-requisito para a inovação no Turismo (Hjalager, 2010).

Arvorece, neste âmbito, uma articulação entre turismo, inovação e região, numa base de governança com propósitos de se afastar das visões monolíticas de desenvolvimento. O conhecimento e a inovação, em tese, são transferidos a partir das interações entre as instituições e organizações de geometrias variáveis, de suas políticas, das instituições de ensino e investigação, das empresas de fomento ao desenvolvimento, do ambiente sociocultural (Carson et al., 2014). Esta teorização tem conformado a lógica dos arranjos produtivos de muitos agentes regionais do turismo, motivados não apenas pela possibilidade de transferência de conhecimento como suporte à inovação, mas, sobretudo pela competitividade com base na cooperação e, por sua vez, geração de desenvolvimento local.

A coesão e o nível de interação entre os envolvidos tornam-se mais apropriados para o contexto dos sistemas de inovação regional do que restringir o sistema organizacional e a gestão do turismo às fronteiras políticas dos territórios turísticos (Bunnell \& Coe, 2001). Salientam Carson et al. (2014) que a proximidade geográfica não é pré-requisito para a troca de conhecimento, uma vez que as redes podem ser estabelecidas de modo inter-regional. Desse modo, Carson et al. (2014) sustentam que uma inovação setorial, como no caso do turismo, deve ser aberta e com suas redes envolvendo diferentes escalas espaciais (regional, nacional, global). Por sua vez, Brandão (2014) salienta que a importância da proximidade geográfica pode depender do estágio de desenvolvimento que se encontra a região turística. A autora exemplifica, de modo empírico, que regiões turisticamente mais desenvolvidas podem apresentar ligações de troca de conhecimento mais externas à região, enquanto que regiões com menor estágio de desenvolvimento podem ter sua base de troca de conhecimento incorporada regionalmente. Em quaisquer das situações, a autora conclui que "a interação com as organizações locais ou regionais é a fonte mais importante de conhecimento" (Brandão, 2014, p. 512).

Aos sistemas de inovação regionais devem se associar universidades, instituições de investigação e agências de transferências de tecnologias, os quais são geradores de atualizados conhecimentos e tendências (Cooke et al.,1997; Scott \& Law, 2006). Também nesta linha de raciocínio, outros fatores são relevantes para a caracterização de um ambiente de inovação regional: (i) recursos naturais; (ii) capital humano (ii); partilha de valores; (iv) cultura de cooperação (Brandão, 2014). Observa-se, portanto, que a inovação regional no turismo é um processo cumulativo e interativo, radicado no território e em redes. Nesta eta-pa de análise, apresenta-se um estudo de ca-so que descreve o Observatório de Turismo do Distrito Federal (OTDF) - Distrito Federal, Brasil -, cuja culminância foi materializada 
pela efetiva interlocução entre seus membros e pela confecção de um produto final, o sistema de monitoramento do turismo regional.

\section{O CASO DO OBSERVATÓRIO DO TURISMO DO DISTRITO FEDERAL (BRASIL)}

Uma experiência de inovação regional em turismo pode ser ilustrada pela implementação do Observatório de Turismo do Distrito Federal (OTDF) e está associada a uma dimensão física, da escala regional do Distrito, enquanto unidade de referência que determinou sua abrangência, e, à dimensão política, como processo que reúne características próprias e convergências estimuladas, principalmente, pela governança, constituindo-se como inovadores para a gestão do turismo, conforme observado em Cherly e Chris (2013) sobre o contexto de formação de redes de governança em turismo.

O Distrito Federal (DF) está situado no planalto central brasileiro, na menor porção física de território do país, porém, equivale em termos de administração política aos demais estados do Brasil. Ao contrário dos municípios que compõem, com autonomia, a divisão territorial em cada estado, o DF é dividido entre regiões administrativas política e orçamentariamente dependentes do governo distrital. Nessa divisão, a Região Administrativa número um, denominada Plano Piloto, integra o chamado Conjunto Urbanístico de Brasília - território protegido legalmen-

\footnotetext{
${ }^{8}$ A cidade de Brasília, capital do Brasil, é inscrita na lista do Patrimônio Mundial da UNESCO desde 1987 (UNESCO, 2015).
}

te por instrumentos legais distritais, federais e compõe a Lista do Patrimônio Mundial da UNESCO $^{8}$ - que concentra grande parte da atividade econômica e dos empregos (Brasil, 2007). Historicamente, sua formação territorial estimulou a formação de uma Rede Integrada de Desenvolvimento Econômico do Distrito Federal (RIDE) que, embora pouco operacional, envolve o seu território associado aos dos municípios de influência nos estados de Goiás (GO), Minas Gerais (MG) e Bahia (BA). Neste aspecto, alude-se à Bunnell e Coe (2011), destacando-se que o Distrito Federal soma-se a outros territórios localizados fora de sua geografia política, compondo uma rede de troca de sinergias externas a seus limites territoriais.

Enquanto destino turístico, as políticas públicas locais e federais, e mesmo o setor produtivo local do turismo, tomam o fato histórico da criação da capital nacional como uma realização inédita do programa modernista brasileiro, tanto por ser um dos marcos do urbanismo do Século XX quanto por impulsionar a arquitetura brasileira, e assumem Brasília enquanto denominação para a promoção do turismo (especialmente o de negócios, mas também o chamado cívico). Se por um lado essa forma pode restringir o acesso ao potencial das atividades turísticas do entorno da Capital (como uma espécie de hub de distribuição regional para o turismo), por outro lado facilita sua identificação e imagem como um destino. Entretanto, o OTDF tomou como base de observação não apenas Brasília, mas a região do Distrito Federal, permi- 
tindo, dessa forma, a consolidação de um sistema aberto de inovação, tal como defendem Carlson et al. (2014) e Cooke et al. (1997).

A dimensão temporal que diz respeito ao surgimento do Observatório enquanto processo de gestão é mais recente do que aquela que consubstanciou o seu território físico e iniciou a partir do marco da instituição do Grupo Gestor do Turismo de Brasília (GGTB), em 2009, por meio do Programa de Regionalização do Turismo - Projeto dos 65 Destinos Indutores ${ }^{9}$. Naquele momento, o GGTB assumiu oficialmente a missão de "Subsidiar a estruturação do turismo e possibilitar a indução da competitividade do destino indutor Brasília, bem como definir parâmetros, propor estratégias e monitorar o Plano de desenvolvimento do Destino até 2014" (GGTB, 2010).

Deste modo, desencadeou-se um processo de concertação política envolvendo a sociedade civil, representada pelo setor de turismo que, em 2010, levou à reativação do Conselho de Desenvolvimento do Turismo do Distrito Federal (Condetur/DF) ${ }^{10}$, instância consultiva e propositiva que, em sua composição, incluiu as mesmas instituições representantes da iniciativa privada, poder público e terceiro setor que compuseram o GGTB, a saber: Associação Brasileira da Indústria de Hotéis (ABIH/DF); Associação Brasileira de Agências de Viagens (ABAV/DF); Associação dos Dirigentes de Vendas e Marketing do Bra-

\footnotetext{
9 O Programa de Regionalização do Turismo do Ministério do Turismo propunha que todas as regiões turísticas fossem coordenadas por grupos gestores, ou seja, grupos de trabalho com representatividade e liderança do setor produtivo local do turismo na região da qual faziam parte, no caso o DF.
}

sil (ADVB/DF); Associação Brasileira de Bares e Restaurantes (ABRASEL/DF); Associação Brasileira de Bacharéis de Turismo (ABBTUR /DF); Associação Brasiliense de Agências de Turismo Receptivo (ABARE/DF); Centro de Excelência em Turismo da Universidade de Brasília (CET/UnB); Sindicato de Turismo Rural e Ecoturismo do Distrito Federal (RURALTUR/DF); Sindicato dos Guias de Turismo do Distrito Federal (SINGTUR/DF); Sindicato de Empresas de Turismo do Distrito Federal (SINDETUR/DF); Brasília e Região Convention \& Visitors Bureau (BRC\&VB); Feiras, Congresso e Eventos do Distrito Federal (SINDEVENTOS/DF); Sindicato de Hotéis Restaurantes, Bares e Similares de Brasília (SINDHOBAR/DF); Fórum das Instituições de Ensino Superior de Turismo do Distrito Federal (FIES/DF); Secretaria de Estado de Turismo do Distrito Federal.

No âmbito do GGTB, tais instituições elaboraram o Plano de Desenvolvimento Turístico do Destino Indutor Brasília que, entre suas metas previu a criação de "um sistema de monitoramento da atividade turística no destino - envolvendo inventário e diagnósticos, considerando aspectos da oferta e da demanda turística" (GGTB, 2010). Ressalte-se que tal necessidade de observação/percepção tanto sobre a oferta quanto a demanda permeou as preocupações do Grupo, sobre maneira, pela falta de informações que auxiliassem até mesmo a estabelecer metas dentro do próprio Plano. Ou seja, não havia a cir-

\footnotetext{
10 O Conselho, com caráter consultivo e propositivo, teve o seu regimento interno e sua composição aprovados por meio do Decreto no 33.525, de 09 de fevereiro de 2012, quando contava com 11 conselheiros do setor público e 21 conselheiros da sociedade civil (Setur/DF, 2014).
} 
culação e troca de informações entre as organizações relacionadas ao setor que permitisse observar uma situação presente com vistas a objetivar em metas aonde se desejaria chegar a uma situação futura. Neste âmbito, alude-se aos estudos de Hall e Willian (2008), Hjaleger (2010) e Carson et al. (2014) no que respeita às sinergias que devem existir na espacialidade entre os diversos agentes interessados no turismo para a condução da atividade turística, estabelecendo vias de transmissão interativa de informação e conhecimento.

Nas oficinas de planejamento realizadas com o propósito de diagnosticar os principais entraves e potencialidades para o desenvolvimento turístico de Brasília, por meio da utilização da metodologia denominada GUT (Gravidade - Urgência - Tendência) o GGTB classificou e priorizou os entraves de- tectados em uma primeira fase. Para tanto, utilizou como documento balizador, entre outros, os Estudos de Competitividade dos Destinos Indutores Regionais, nos anos de 2008 e $2009^{11}$. Tais estudos apontaram que em relação à dimensão das Políticas Publicas o Destino Indutor Brasília carecia de: (i) marco legal constituído (política pública formalizada); (ii) de ações e resultados vinculados à cooperação regional (no Centro Oeste do País) e (iii) do monitoramento da atividade turística, conforme Tabela 2. Estes resultados foram possíveis pela troca de conhecimento tácito constituído de modo organizacional e socialmente pelas contribuições dos integrantes da governança (Gibbons, 1994), como também pela base de conhecimento explícito (Albernath \& Clark, 1985) fomentado por estudos formais previamente realizados para a região.

Tabela 02 - Análise da Competitividade no Destino Indutor Brasília

\begin{tabular}{|c|c|c|}
\hline \multirow{4}{*}{$\begin{array}{l}\text { Dimensão } \\
\text { Políticas } \\
\text { Públicas }\end{array}$} & Variáveis & Análise \\
\hline & Política pública & $\begin{array}{l}\text { [...] não existe modelo de planejamento formal para o setor turís- } \\
\text { tico. Da mesma forma, no momento da pesquisa, a instância de go- } \\
\text { vernança local representada pelo CONDETUR - Conselho de Desen- } \\
\text { volvimento do Turismo encontrava-se inativo. }\end{array}$ \\
\hline & Cooperação regional & $\begin{array}{l}\text { [...] não existe um plano de desenvolvimento turístico integrado da } \\
\text { região do qual o destino faça parte. }\end{array}$ \\
\hline & Monitoramento & $\begin{array}{l}\text { Não é realizado tampouco o monitoramento dos impactos econô- } \\
\text { micos, sociais e ambientais gerados a partir da atividade turística } \\
\text { [...]. Não existe nenhum sistema ou conjunto de indicadores de de- } \\
\text { sempenho do setor, nem é elaborado um inventário técnico de es- } \\
\text { tatísticas turísticas. }\end{array}$ \\
\hline
\end{tabular}

Fonte: FGV/Mtur/Sebrae (2009) ${ }^{12}$.

11 Realizado pela primeira vez em 2007, fruto de parceria entre o Ministério do Turismo, o Serviço Brasileiro de Apoio às Micro e Pequenas e Empresas (SEBRAE/Nacional) e a Fundação Getúlio Vargas.
12 Disponível em:http://www.turismo.gov.br/sites/default/turismo/o_ministerio/publicacoes/Indice_competitividade/2009/BRASILIA_Relatorioanalitico2009\%20ok.pdf 
Assim figurou na proposta do Plano, bem como no planejamento do GGTB a proposta de ação para a criação de um sistema de monitoramento do turismo no
Distrito Federal (Tabela 3), até então denominado de Sistema de Estatísticas do Turismo ${ }^{13}$, que permitisse concentrar dados e informações do turismo.

Tabela 3 - Ação do Plano de Desenvolvimento Turístico do Destino Indutor Brasília

\begin{tabular}{|c|c|}
\hline Variável & Sistema de Estatística do Turismo \\
\hline AÇÃO 01 & $\begin{array}{l}\text { Criar um sistema de monitoramento do turismo no Distrito Federal } \\
\text { (Observatório do Turismo) }\end{array}$ \\
\hline DESCRIÇÃO & $\begin{array}{l}\text { Conceber e implantar um sistema de monitoramento do turismo no Distrito Federal para } \\
\text { subsidiar o planejamento, a gestão, a avaliação e o acompanhamento da movimentação da } \\
\text { atividade turística. }\end{array}$ \\
\hline METAS & $\begin{array}{l}1 \text { Criar e implantar o sistema de monitoramento do turismo do DF até dezembro } 2010 \\
2 \text { Implementar o sistema de monitoramento até outubro de } 2011 \\
3 \text { Apoiar a criação do Instituto de Pesquisas Turísticas do Distrito Federal }\end{array}$ \\
\hline
\end{tabular}

Fonte: Adaptado de GGTB (2010)

Como continuidade do trabalho do GGTB a proposta de implementar o monitoramento da atividade turística no DF, legitimada no processo de planejamento do GGTB, foi encampada no plano estratégico da Secretaria de Estado de Turismo do Distrito Federal, com a proposta do Projeto de Implantação do Observatório de Turismo do Distrito Federal. Essa proposta foi licitada em chamada pública ${ }^{14}$ em 2011, com início do projeto no final desse ano, demonstrando um aspecto importante e que deve ser ressaltado enquanto processo de construção de política pública, pois a partir do compartilhamento das necessidades entre os diferentes interesses em jogo, de cada um dos agentes envolvidos, produziu-se uma ação de consenso a partir da validação de uma convergência dos interesses, e, em um processo de continuidade de ações.

Essa experiência inicial, até a sua materialização institucional como suporte para a elaboração e implementação de política pública $^{15}$ - consolidou, enquanto processo inovador, uma tônica de conectividade e interatividade entre as organizações relacionadas ao turismo (Cherly \& Chris, 2013) que se estendeu até à conclusão da execução do Projeto. Entendase que conexão e interação envolvem na

\footnotetext{
${ }^{13}$ Nomenclatura influenciada pela demanda da Organização Mundial do Turismo (OMT) em criar uma Conta Satélite.

${ }^{14} \mathrm{O}$ resultado da licitação contemplou o Centro de Excelência em Turismo da Universidade de Brasília na sua execução.

${ }^{15}$ O OTDF surgiu como proposta de política pública, associado, no processo, em 2012, à promulgação da Lei № 4.883 , de 11 de julho de 2012 que instituiu a política de turismo do Distrito Federal. Nesse documento o OTDF figura como um "instrumento de gestão do órgão oficial de turismo, responsável pela organização, sistematização, disponibilização e disseminação das pesquisas estudos e dados do Distrito Federal disponibilizados pelas entidades públicas e privadas que atuam no setor turístico." O documento que traz na íntegra a Política de Turismo do Distrito Federal encontra-se disponível em: http://observatorio.setur.df.gov.br/files/8714/2382/4476/Lei_4.883_de_11_de_setembro_de_2012.pdf
} 
realidade de estudo situações de tensão e conflito mediadas, quase sempre, nos encontros do Condetur/DF.

Para garantir o processo participativo no contexto do turismo local, sustentável na forma de uma governança ideal, entre os produtos gerados pelo Projeto houve o da Gestão Participativa que ampliou a conexão e interação tanto em encontros específicos com representantes do setor produtivo local do turismo como os de mobilização e envolvimento com agentes indiretamente relacionados. As ações de mobilização das Regiões Administrativas foram fundamentais para o entendimento e a realização do Produto Inventário da Oferta Turística, bem como a participação dos setores privados na construção das pesquisas, como na Pesquisa de Perfil e Satisfação dos Turistas e no Monitoramento, possibilitaram ajustes nos intrumentos de pesquisa. Foram inúmeros encontros externos e internos (no âmbito do Conselho de Desenvolvimento do Turismo do Distrito Federal) que permitiram boa comunicação, sensibilização e participação, conformando laços de interação para a difusão do conhecimento tácito, nesta rede de comunicação (Gibbons, 1994; Brandão, 2014).

Nesse sentido, o nivelamento da linguagem adotada no Projeto de Implantação do OTDF trouxe aos agentes envolvidos o entendimento comum sobre a criação de um "marco zero" de dados e informações provenientes da observação do turismo de forma que ao longo do tempo diversos "retratos" da realidade observada permitissem adequar a sua gestão ao planejamento, aos programas e projetos.

Destarte, Brandão (2014) salienta que a expertise dos recursos humanos são fontes de geração de conhecimento quando um sistema organizacional ou operacional, como o turismo, a promove. Nesta concepção, a participação do Centro de Excelência em Turismo da Universidade de Brasília CET/UnB representou um diferencial significativo na condução do processo de implantação do OTDF em diferentes sentidos, dos quais destacam-se dois: (i) a possibilidade de articular e reunir o conhecimento produzido na Universidade para a construção dos produtos demandados; (ii) a condução do processo em um regime de gestão participativa, dialógico, que intensificou no máximo a comunicação necessária com e entre os diversos interlocutores, aspecto essencial no seu envolvimento e participação na construção do conhecimento para o Observatório.

Além da dimensão do conhecimento explícito, o CET/UnB pode transmitir à rede instituída, seu conhecimento do "saber fazer" pelo acúmulo de outras experiências na condução de governanças e observatórios. A participação do CET/UnB, assevera indispensável participação de instituições de ensino e centros de investigação no processo de inovação regional no turismo (Cooke et al., 1997; Scott e Law, 2006; Brandão, 2014; Carson et al., 2014).

Todavia, para a manutenção desse fator conectividade/interatividade da rede instituída, combinado com o que se denominou Gestão Compartilhada, foi igualmente importante o suporte das Tecnologias da Informação e Comunicação (TICs). Todo o conceito das TICs como força indutora para inovação 
tem atraído interesse significativo de diversos investigadores (Hjaleger, 2010). Este estudo de caso alinha-se com a afirmação da autora uma vez que houve a implementação de uma ferramenta TIC que permitiu elaborar de forma compartilhada um banco de dados e informações que comporta a coleta, o armazenamento e o tratamento de dados e informações para o planejamento e a gestão do setor. $\mathrm{O}$ instrumento denominado de Sistema Informatizado de Dados (SID) para o Observatório do Turismo no Distrito Federal teve sua arquitetura originalmente concebida em sete módulos funcionais: 1 - o Módulo da Oferta Turística (Inventário); 2 - o Módulo de Monitoramento; 3 - o Módulo de Demanda (Perfil e Satisfação); 4 - o Módulo de Mineração de Dados Web; 5 - o Módulo da Plataforma Embarcada; 6 - o Módulo de Visualização de Resultados e Geração de Relatório, e; 7 - o Módulo Portal do Observatório.

O Portal do Observatório ${ }^{16}$ foi 0 módulo final que permitiu a interação à distância tanto para o público em geral quanto para o acesso selecionado aos participantes do setor de turismo. A figura 2 apresenta a máscara da página principal do portal. Nele o OTDF é definido como:

\begin{abstract}
Ferramenta de observação, coleta, tratamento, análise, geração e monitoramento de dados e informações. Instrumento de suporte para o planejamento, a gestão e o monitoramento do fenômeno turístico destinado a subsidiar as decisões empresariais de investimentos e a construção de políticas públicas do destino Brasília (GGTB, 2010).
\end{abstract}

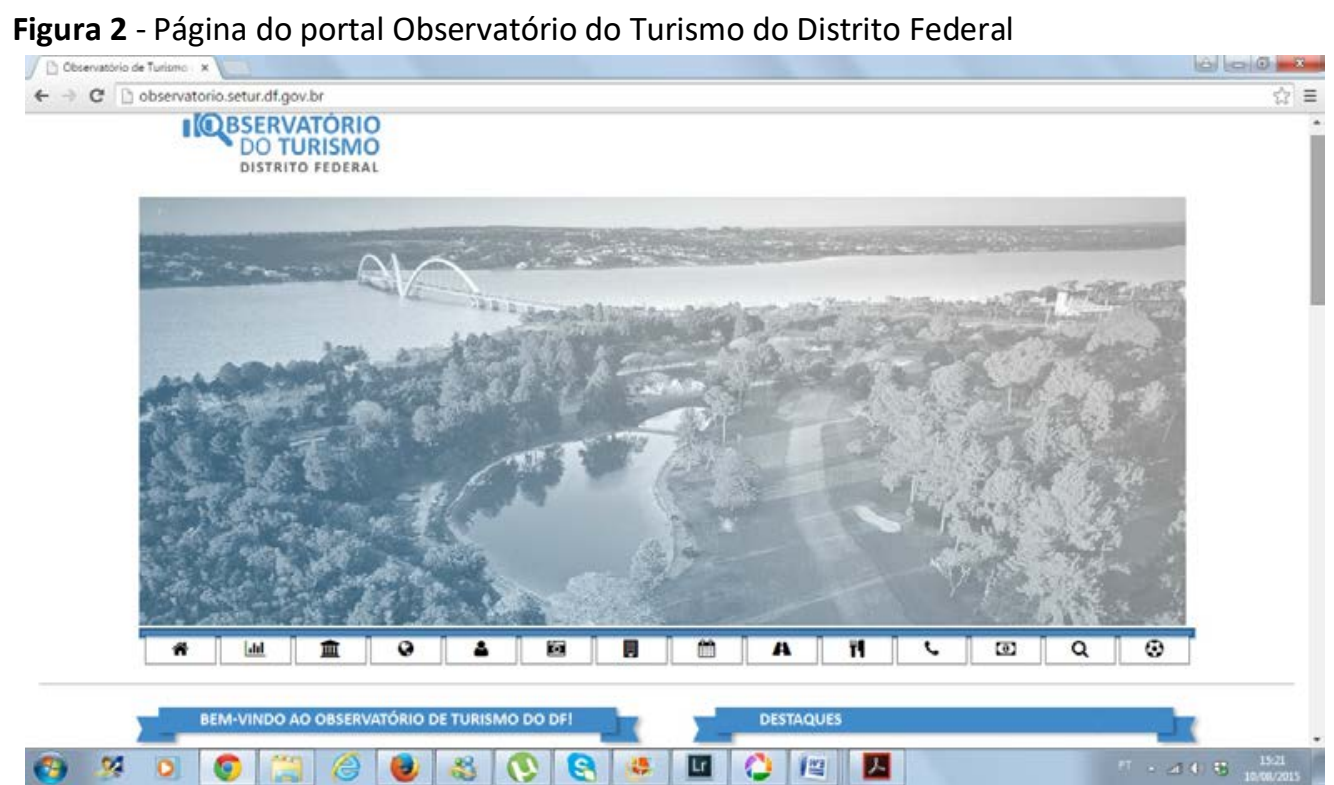

Fonte: http://observatorio.setur.df.gov.br/

${ }^{16}$ Disponível em: http://observatorio.setur.df.gov.br/ 


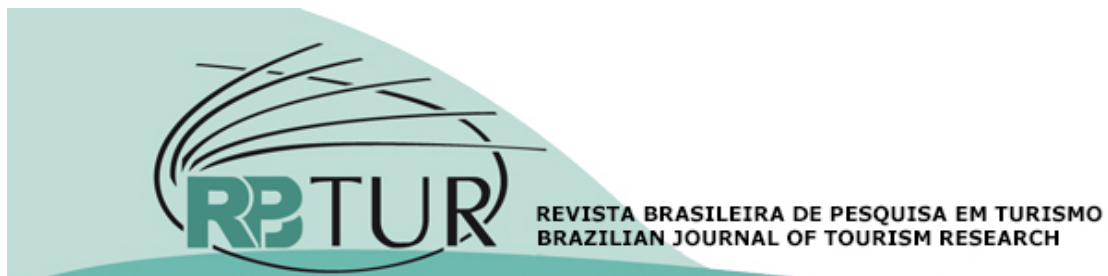

Após o encerramento do Projeto de Implantação do Observatório de Turismo do Distrito Federal dois aspectos são de importante menção: i) A gestão governamental que o concebeu deu continuidade às ações necessárias para a alimentação de dados e informações, ampliando as possibilidades de comunicação ao concentrar no Portal outros estudos e pesquisas por ela realizados, como, por exemplo, os relatórios e pesquisas da Copa do Mundo FIFA 2014. Ressalte-se nessa ampliação a permanência de uma interface de consulta amigável sempre mantida; ii) Estima-se que ainda não houve a apropriação plena do OTDF, tanto por parte do setor público quanto do setor privado. A mudança recente da condução política do governo local, bem como das combinações de interesses e pactos privados e/ou públicos em prol do turismo no Distrito Federal lançaram um novo momento e desafio no processo de governança. Esse diz respeito à perspectiva da continuidade de projetos de gestão pública, especialmente os que conquistaram resultados positivos para que o turismo possua maior e comprovada visibilidade por meio das pesquisas e estudos que geram dados e informações fundamentais ao seu entendimento para o planejamento e a gestão e percepção do papel do conhecimento produzido, seja explícito ou tácito, na inovação no turismo.

\section{CONSIDERAÇÕES FINAIS}

A inovação é apontada como um processo que traz benefícios e crescimento articulado para a estrutura das regiões turísticas.
Esta lógica, porém, dependerá do nível de gregariedade regional dos agentes do turismo, da força das interações entre os participantes da rede, da cumulação de experiências e da transmissão de conhecimentos explicitos e tácitos conjuntamente.

Observou-se, neste trabalho, que o papel público nas políticas de inovação regional tem sua ênfase na coordenação das sinergias e interlocuções, bem como na mediação de conflitos e fornecimento de investimentos necessários à concertação regional. Não menos importante foi o papel identificado pelas instituições de ensino e centros de investigação que dão velocidade aos processos de inovação pela capacidade de geração e transmissão de conhecimento e contribuição à gregariedade do arranjo cooperativo territorial do turismo.

A operacionalização do OTDF mostrou que práticas sinérgicas entre os agentes diretamente e indiretamente envolvidos com o turismo no âmbito da região do Distrito Federal podem produzir resultados concretos no sentido de viabilizar o planejamento, a gestão e a competitividade do destino turístico. A articulação pautada na gregariedade e interlocução regional demonstrou que existe uma vinculação estreita entre troca de conhecimentos e inovação, pela consecução de um produto inovador para o planejamento e para a gestão do turismo, denominado "Portal do Observatório". Nele, para além da convergência de informações e indicadores, consolidados por um corpus de dados fornecidos pelos principais agentes do turismo no DF, 
materializou-se, também, laços integradores entre estes agentes, pela multiplicidade de ligações necessárias à coleta, avaliação e tratamento dos dados.

De resto, recomenda-se a aplicação do presente estudo de caso em outros destinos observando as suas especificidades regionais. Para esta replicação, sugere-se a identificação de fontes chaves produtoras e disseminadoras de conhecimentos explícito e tácito, os quais devem somar-se à instância de governança regional do turismo. Estas fontes devem ocupar posições estratégicas de modo a facilitar o fluxo de informações nos domínios inter e intra regionais.

O presente estudo de caso abre uma agenda de investigação sobre o tema inovação regional em turismo no Brasil onde são destacados os seguintes tópicos: (i) sugeremse estudos que utilizem técnicas sociométricas para identificar as sinergias mais relevantes no domínio de uma instância de governança regional em turismo; (ii) as mesmas técnicas podem produzir estudos que identifiquem quais instituições são determinantes para a produção e transferência do conhecimento da inovação regional em turismo no Brasil; (iii) qual o papel das populações anfitriães na produção de conhecimento para a inovação regional em turismo? (iv) que aplicações práticas resultam da produção e transferência de conhecimento a partir da inovação regional em turismo no Brasil? Pesquisas futuras sobre estas questões contribuirão para a compreensão sobre a inovação regional em turismo no Brasil.
Albernath, W., \& Clark, K. (1985). Innovation: mapping the wing of creative destruction. Research Policy, 14, 3-22.

Aldebert, B., Dang, R. J., \& Longhi, C. (2011). Innovation in the tourism industry: The case of Tourism@.Tourism Management, 32(5), 12041213.

Alves, S., Vabo Junior, L., Vaz, L., \& Salomão, R. (2009). Cenários para a Indústria de Turismo e Viagens - Um Ecossistema em Transformação. In XXIII Encontro nacional da Associação Nacional de Pós-Graduação e Pesquisa em Administração (EnANPAD). Brasil.

Beni, M. (2001). Análise estrutural do turismo (4a ed.). São Paulo: Senac.

Brandão, F. (2014). Innovation in tourism: the role of regional innovation systems. Aveiro: Tese de Doutorado. Departamento de Economia, Gestão, Engenharia Industrial e Turismo. Universidade de Aveiro.

Brasil (2007). Plano Piloto 50 anos: cartilha de preservação. Brasília, DF: IPHAN / 15a Superintendência Regional.

Bunnell, T. G., \& Coe, N. M. (2001). Spaces and scales of innovation. Progress in Human Geography, 25(4), 569-589.

Buhalis, D., \& O'Connor, P. (2006). Information, communication, technology: revolutionizing Tourism. In D. Buhalis \& C. Costa (Eds.), Tourism management dynamics: trends, management and tools (pp. 196-209). Oxford: Elsevier.

Carson, D. A., Carson, D. B., \& Hodge, H. (2014). Understanding local innovation systems in peripheral tourism destinations. Tourism Geographies, 16(3), 457-473.

Castells, M. (2007). A sociedade em rede (10a ed.). Rio de Janeiro: Paz e Terra.

\section{REFERÊNCIAS}


Cezário, D.; Pena, L. (2016). Redes de colaboração e o financiamento coletivo de projetos de turismo responsável no Brasil. In VII Congreso Latinoamericano de Investigación Turística (CLAIT). Equador.

Chang, A., Go, F., \& Pine, R. (1998). Service innovation in Hong Kong: attitudes and practise. The Services Industries Journal, 18(2), 112-124.

Cherly, C., \& Chris, C. (2013). Perspectives and Trends on Knowledge Management: European Agencies and Initiatives. In C. Costa, E. Panyk, \& D. Buhalis (Eds.), European Tourism Planning and Organisation Systems: New Perspectives and Emerging Issues (pp. 326-338). Bristol: Channel View publication.

Cooke, P., Uranga, M. G., \& Etxebarria, G. (1997). Regional innovation systems: Institutional and organisational dimensions. Research Policy, 26, 475-491.

GGTB (2010). Plano de Desenvolvimento do Destino Indutor Brasília, ETAPA I, 3a versão.

Gibbons, M. (1994). Transfer Sciences: Management of Distributed Knowledge Production. In M. Gibbons, H. Nowotny, P. Scott, S. Schwartzman, \& M. Trow (Eds.), The new production of knowledge: the dynamics of science and research in contemporary societies (pp. 259270). London: Sage.

Gretzel, U., Werthner, H., Koo, C., \& Lamsfus, C. (2015). Conceptual foundations for understanding smart tourism ecosystems. Computers in Human Behavior, 50, 558-563.

Halkier, H., Kozak, M., \& Svensson, B. (2014). Innovation and Tourism Destination Development. European Planning Studies, 22(8), 1547-1550.

Hall, M., \& Williams, A. (2008). Tourism and innovation ( 2 a ed.). New York: Routledge.

Hjalager, M. (2013). 100 Innovations that transformed Tourism. Journal of Travel Research,
54(1), 3-21.

Hjalager, M. (2010). A review of innovation research in tourism. Tourism Management, 31(1), 1-12.

Hoarau, H., \& Kline, C. (2014). Science and industry: Sharing knowledge for innovation. Annals of Tourism Research, 46, 44-61.

Hollinshead, K. (2004). A prime in ontological craft: the creative capture of people and places through qualitative research. In J. Philmore \& L. Goodson (Eds.), Qualitative research in tourism: ontologies, epistemologies and methodologies (pp. 63-82). New York, Paris: Routledge.

Lemos, C. (1999). Inovação na era do conhecimento. In H. Lastres \& S. Albagli (Eds.), Informação e globalização na era do conhecimento (pp. 122-144). Rio de Janeiro: Campos.

Litvin, S. W., Goldsmith, R. E., \& Pan, B. (2008). Electronic word-of-mouth in hospitality and tourism management. Tourism Management, 29(3), 458-468.

Luo, Q., \& Zhong, D. (2015). Using social network analysis to explain communication characteristics of travel-related electronic word-of-mouth on social networking sites. Tourism Management, 46, 274-282.

Minazzi, R. (2015). Social Media Marketing in Tourism and Hospitality. New York: Springer.

Scott, N., \& Laws, E. (2006). Knowledge sharing in tourism and hospitality. Journal of Quality Assurance in Hospitality \& Tourism, 7(1/2), 1-12.

SETUR DF (2014). Conselho de Desenvolvimento do Turismo do Distrito Federal. Recuperado em 10 de fevereiro de 2016 de http://observatorio.setur.df.gov.br/index.php/g overnanca/condeturdf/

Sigala, M. (2014). Collaborative commerce in tourism: implications for research and industry. Current Issues in Tourism, (June), 1-10. 
Wang, D., Li, X. (Robert), \& Li, Y. (2013). China's "smart tourism destination" initiative: A taste of the service-dominant logic. Journal of Destination Marketing \& Management, 2(2), 59-61.

Williams, A. M., \& Shaw, G. (2011). Internationalization and innovation in tourism. Annals of Tourism Research, 38(1), 27-51.

Zhang, C., \& Xiao, H. (2014). Destination development in China: towards an effective model of explanation. Journal of Sustainable Tourism, 22(2), 214-233.

UNESCO (2015). Patrimonio Mundial no Brasil. Recuperado em 20 de julho de 2015 de http://www.unesco.org/new/pt/brasilia/culture/world-heritage/list-of-world-heritage-inBrazil/

Dados dos Autores

\section{Luis Henrique Souza}

Graduado em Turismo pela Universidade Federal de Pernambuco (UFPE), Mestre em Turismo pelo Programa de Mestrado em Gestão e Desenvolvimento em Turismo da Universidade de Aveiro - Portugal. Doutorando em Turismo pela Universidade de Aveiro (Programa Doutoral em Turismo). Atuou como analista em turismo e professor dos cursos de especialização do Centro de Excelência em Turismo da Universidade de Brasília (CET-UnB); coordenador do curso de Turismo da Universidade Federal de Sergipe e atualmente é professor adjunto do Departamento de Hotelaria e Turismo da UFPE. luis rce@yahoo.com.br

\section{Luiz Carlos Spiller Pena}

Professor Adjunto da Universidade de Brasília(UnB). E-mail: spilena@gmail.com

\section{Marutschka Martini Moesch}

Professor Adjunto da Universidade de Brasília (UnB). E-mail: marumoesch@gmail.com 